\title{
Automatic classification of density and magnetic domains from the Carajás mineral province
}

Aisengart, T. ${ }^{\star}$,Geosoft Latinoamérica ; Ando, J.L. ,Geosoft Latinoamérica; Batista, L. ,Geosoft Latinoamérica; Ferreira, L.C. ,Geosoft Latinoamérica

Copyright 2019, SBGf - Sociedade Brasileira de Geofísica

This paper was prepared for presentation during the $16^{\text {th }}$ International Congress of the Brazilian Geophysical Society held in Rio de Janeiro, Brazil, 19-22. August 2019.

Contents of this paper were reviewed by the Technical Committee of the $16^{\text {th }}$ International Congress of the Brazilian Geophysical Society and do not necessarily represent any position of the SBGf, its officers or members. Electronic reproduction or storage of any part of this paper for commercial purposes without the written consent of the Brazilian Geophysical Society is prohibited.

\begin{abstract}
In southern Pará, Carajás Mineral Province (CMP) is known for the broad potential exploration associated with several metallogenic occurrences. Due to it, this paper presents an innovative technique to corroborate with the description of already known targets and with the identification of new mineral exploration targets based on the integration of different geophysical methods: gravity and magnetic. On this, the Self-Organizing Maps (SOM) was applied to a regional airborne geophysical data and it was used to identify density and magnetic domains, this technique providing as input the density and magnetization models obtained, respectively, from gravimetry data inversion and the magnetization vector inversion (MVI). The SOM was tested separately with the magnetization model and, subsequently, through integrating the magnetization and density models from CMP. These two results from SOM were compared and allowed us a better characterization of the Carajás Mineral Province and its targets from a regional perspective.
\end{abstract}

\section{Introduction}

The recent availability of airborne geophysical data by the Brazilian Geological Survey (CPRM), allows the regional study of several areas. Combining this availability with the application of inversion and classification algorithms to data from Carajás Mineral Province (CMP), that includes magnetic and gravity data, allowed us to identify the most important mineral deposits in this area.

The data used was acquired in 2013/2014 at an elevation of $900 \mathrm{~m}$ and with N-S flight lines with $3000 \mathrm{~m}$ separation. Although, with this resolution it is only possible a regional study, the methodology used has been demonstrated to be a powerful tool to generate targets in an automated way as it confirmed known deposits already being explored and indicated new targets.

Through inversion of the geophysical data we created the density and magnetization model with resolution of $1000 \times 1000 \times 200 \mathrm{~m}$, considering the survey parameters, the area covered $(390 \times 370 \mathrm{~km})$ and the existing limits of available computational power, which together defines the dimensions of the matrix to be inverted.

The study area is limited to the North by granites of high degree of metamorphization of the Bacajá Domain (BD), to the east by the metassedimentary rocks of the Araguaia Belt and to the west by volcanic rocks and granitoids of the Iriri-Xingu Domain (IXD). CMP is inserted in the centralsouthern range of the survey, in the South with predominance of greenstones belts of Rio Maria Domain (RMD) and in the central area metavulcanosedimentary sequences and rare ultramafic units, with predominance of granites of the Carajás Domain (CD) ),(CPRM PGB Pará, 2008) (Figure 1).

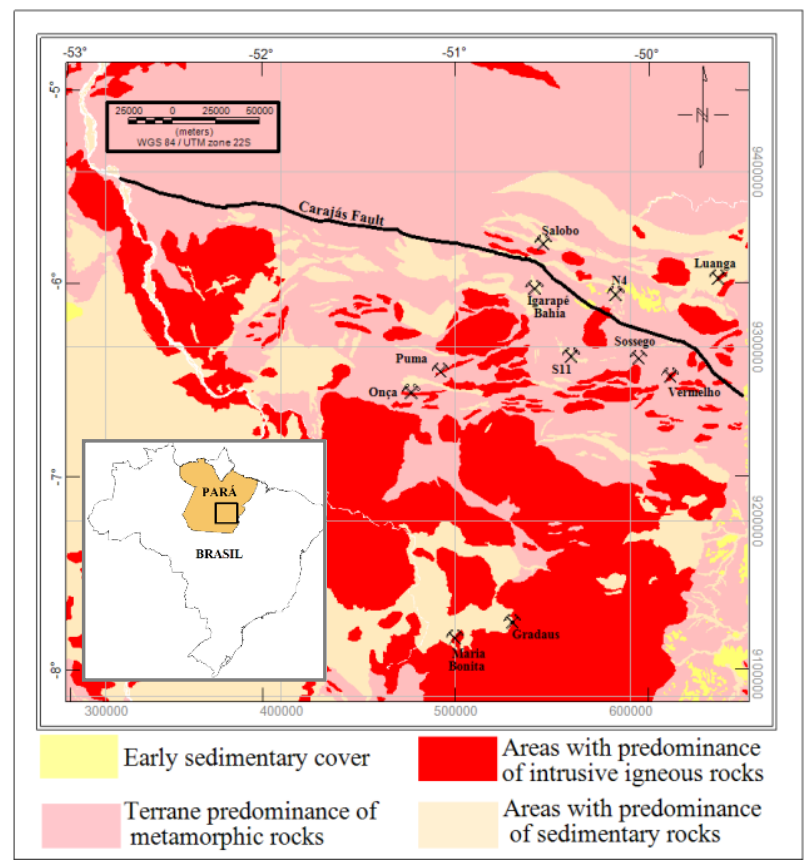

Figure 1: Location of the CMP. Modified from Mapa Geológico Simplificado do Brasil (CPRM, 2015).

In this study, the Self-Organizing Maps (SOM) technique was applied to separate the anomalies from the background and then classify the anomalies. The Cartesian components of the vector resulting from the MVI $(\mathrm{Vx}, \mathrm{Vy}, \mathrm{Vz})$ in conjunction with the Cartesian coordinates $(\mathrm{X}, \mathrm{Y}, \mathrm{Z})$ were used to automatically characterize the magnetization domains and also SOM was used to classify the MVI cartesian components together with the density values $(\rho)$ from gravity data and the Cartesian coordinates $(\mathrm{X}, \mathrm{Y}, \mathrm{Z})$ as the input to generate an unsupervised classification and this joint classification was used to generate targets.

\section{Methodology}

\subsection{Magnetization Vector Inversion (MVI)}

Measuring the magnetic field $B$ in a series of locations $r$ gives the forward equation for the Magnetic Vector (Ellis et al, 2012):

$$
B_{\beta\left(r_{j}\right)}=\sum_{K, a}^{N, 3} m_{k, a} \int_{v_{k}} \partial_{\alpha} \partial_{\beta} \frac{1}{\left|r-r_{j}\right|} d r^{3}(1)
$$


Through the discretization of equation (1) is possible to get the equation for the direct problem:

$$
B_{(r)}=\nabla \int_{v} M\left(r^{\prime}\right) \cdot \nabla^{\prime} \frac{1}{\left|r-r^{\prime}\right|} d r^{\prime 3}
$$

That can be simply represented as:

$$
B=\mathrm{Gm}
$$

The Magnetization Vector Inversion problem is to solve for $m$, given $B$. However, is necessary to subject $B$ to regularization conditions to be able to resolve this inverse problem.

The implementation that has been used in this work applied the Tikhonov minimum gradient regularizer (Zhdanov, 2002) to solve the inverse magnetic problem for the magnetic vector by minimizing the difference of the calculated and measured magnetic field. Until recently the physical property used to describe magnetic material in the earth, particularly for inversion, was the susceptibility. The relationship between susceptibility and magnetization is as follows:

$$
\vec{M}=k \vec{H}_{e}
$$

The hypothesis adopted for this description is that the direction of the induced field is aligned with the direction of the Earth's magnetic field, that is the magnetization vector is aligned with the inducing field, the Earth's field direction. However, the complex nature of rocks demands a more general description of their magnetic properties. Thus, we introduce the anisotropic susceptibility that allows to generalize the scalar susceptibility to a vector susceptibility with three components (kx, ky, kz), with the amplitude of the anisotropic susceptibility being just the scalar susceptibility.

The Magnetization Vector Inversion (MVI) used to develop this paper is based on this effective susceptibility that includes the anisotropic and remnant magnetization as described in equation (5) (Aisengart, 2015):

$$
\vec{M}=\left(\vec{k}+\vec{k}_{R}\right) H_{e}=\vec{k}_{M V I} H_{e}
$$

\subsection{Gravity Inversion}

The gravity inversion has generated an unconstrained density model, that is, inverting gravity measured data generates a density model with no a priori geologic knowledge from the study area. In the case of gravimetry, the inversion allows to estimate a density model, that is a scalar physical quantity, while for the magnetic method the inversion estimates the variation of magnetization that is a vector physical quantity with direction and intensity. This physical characteristic of magnetization makes the inversion of magnetic data more complex than inversion of gravity data.

On this, due to the non-unicity of potential field models, when other data is available, constrained inversion might give a more accurate model of the subsurface, but unconstrained inversions helps understanding and target generation in early exploration stage.

\subsection{Self-Organizing Maps (SOM)}

SOM is an unsupervised classification technique used to analyze and visualize large-scale data. It is based on the principles of measures of quantization vector and this technique has proved itself as an ideal tool to analyze a data set with disparate geophysical parameters. It works based on the preservation of the properties of the bodies and nearby input patterns activate nearby output patterns, generating an automatic classification of the input data. In this paper SOM was used to identify and classify automatically the main magnetic anomalies resulting from the MVI, as has already been successfully applied in other regional datasets (Aisengart et al. 2017; Aisengart et al 2018). In this work, this technique was also used to identify and classify integrated models of magnetization and density. Figure 2 presents a simplified workflow applied to this study.

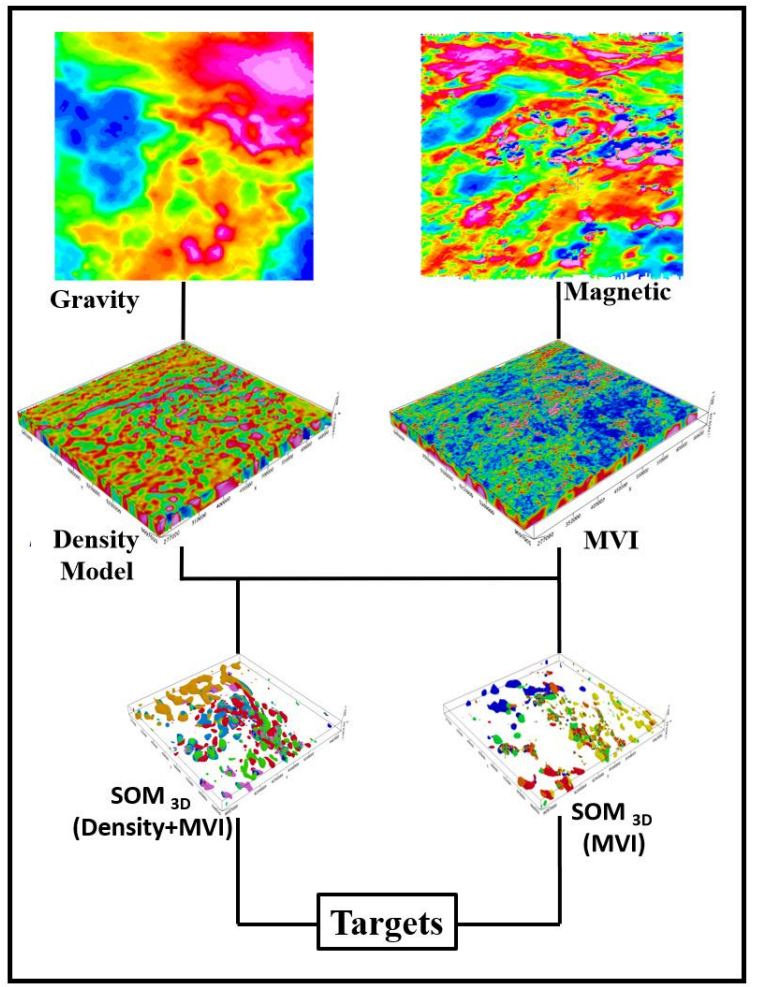

Figure 2: Workflow applied to the study.

\section{Examples}

The described workflow was applied to the regional data from CMP resulting in a magnetization vector voxel and a density model. The results from the MVI were also exported to a database and the density values sampled into the same database, that was used, together with the cartesian coordinates, as input for the SOM unsupervised classification. We normally use $10-15 \%$ as anomalous, depending on the area, but as a mineral province and considering the number of anomalies present in the study area, in this case we have tested also considering $20 \%$ of the area as anomalous and 9 classes and this was the best result found.

Automatic classification of magnetic domains using MVI and SOM has already been successfully applied in several areas (Aisengart et al., 2017) and in this study, the 
inclusion of the density model has provided considerable additional insight.

\section{Results}

The resulting classes considering only MVI results and the combined magnetic and density ones were integrated with the available information from Mineral Resources from CPRM and known mine locations and we have selected two mines in the region to corroborate the results: Sossego and Salobo.

The best way to visualize such information is in section view as it allows also to have a gross estimate of the extension and depth of the targets. In order to be able to compare the results, in Figure 3 are presented the location of the profiles.

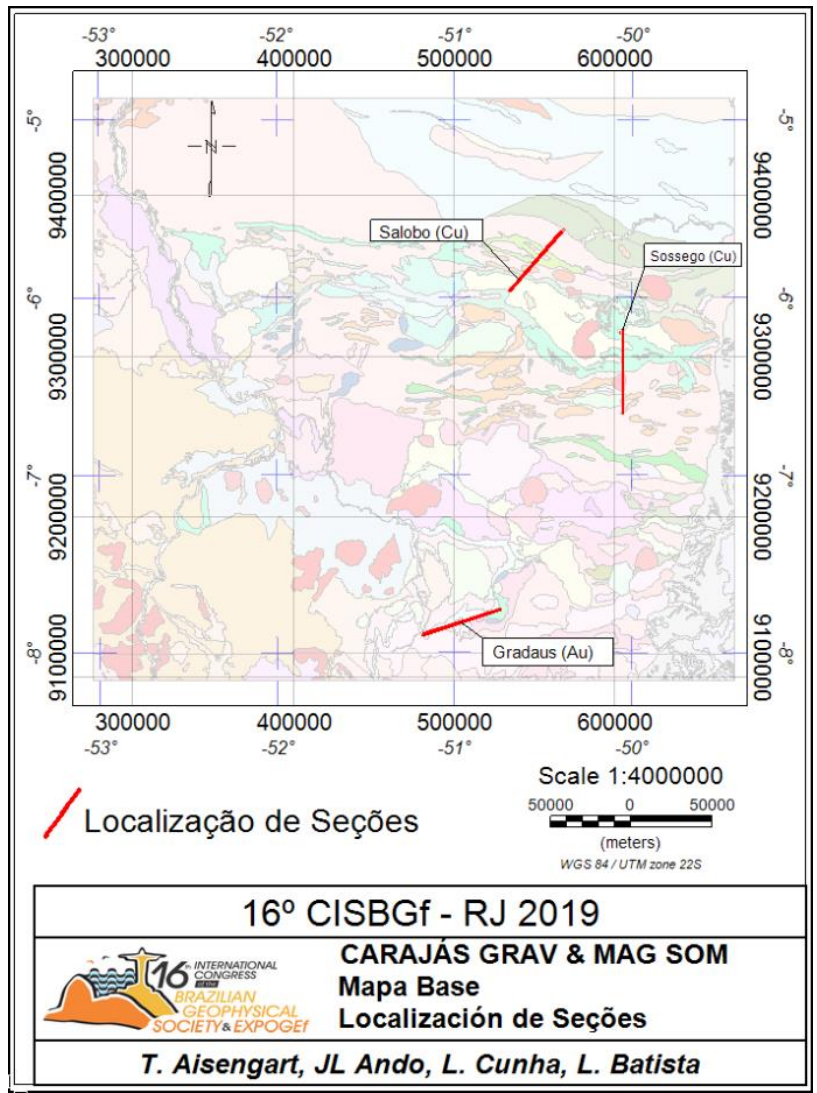

Figure 3: Geological map of the study area with the section locations.

Figure 4 presents three windows where, from bottom to top, are included the section view with the SOM classes, a plan view with the geologic map and three profiles from surface: the bouguer anomaly in black, magnetic intensity in red and the analytic signal in blue.

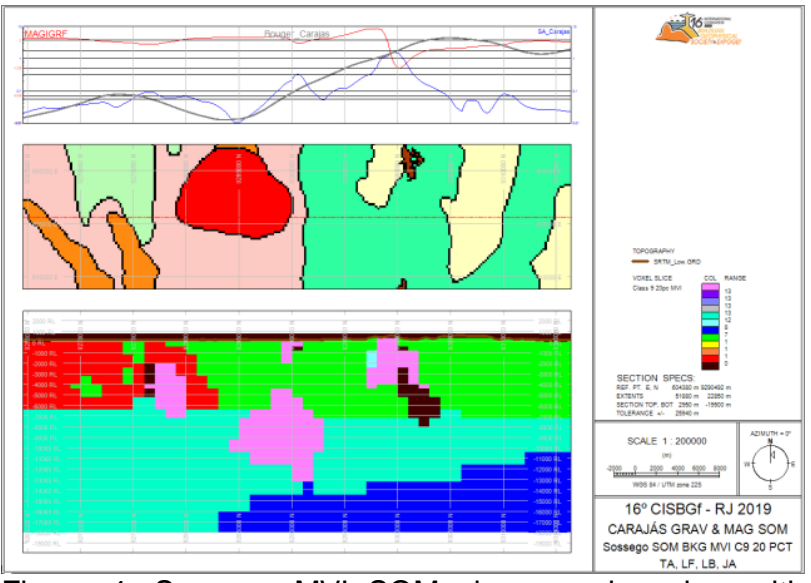

Figure 4: Sossego MVI SOM classes, plan view with geological map and profiles from surface data

In Figure 5 the only change for sake of comparison are the SOM classes that were generated using both the magnetization and density models.

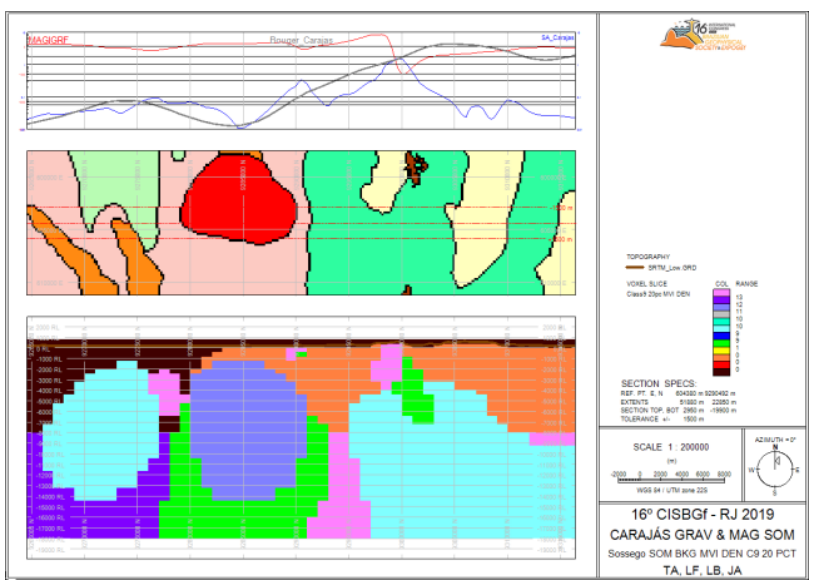

Figure 5: Sossego MVI and Density SOM classes, plan view with geological map and profiles from surface data

The same view is presented in figures 6 and 7 for the Salobo mine.

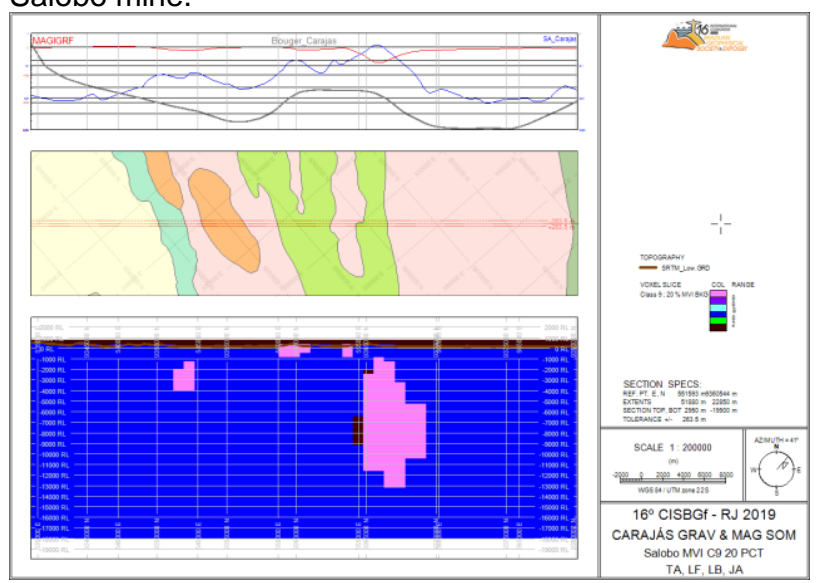

Figure 6: Salobo MVI SOM classes, plan view with geological map and profiles from surface data. 


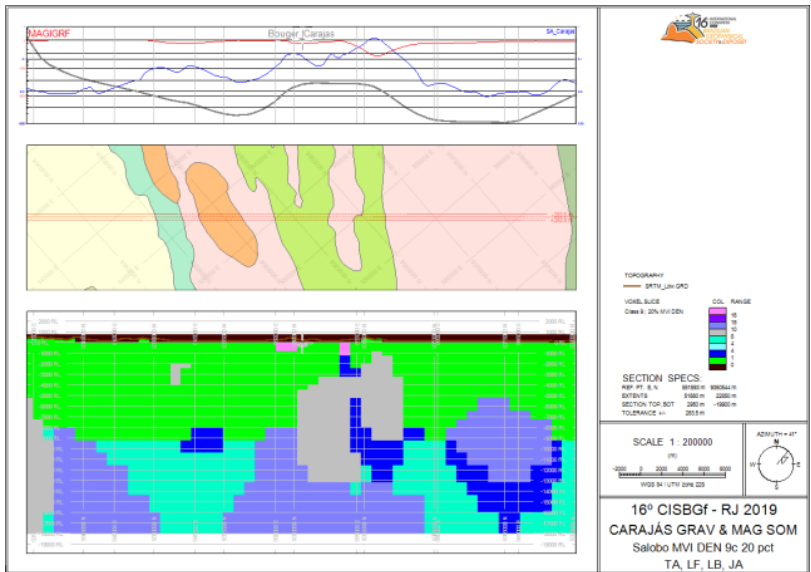

Figure 7: Salobo MVI SOM and Density classes, plan view with geological map and profiles from surface data.

Based on the very good correlation showed by the known targets with the anomalous classes as generated by the SOM analysis of the magnetization and density models, we have also investigated other targets using the same methodology, including Gradaús (Figures 8 and 9).

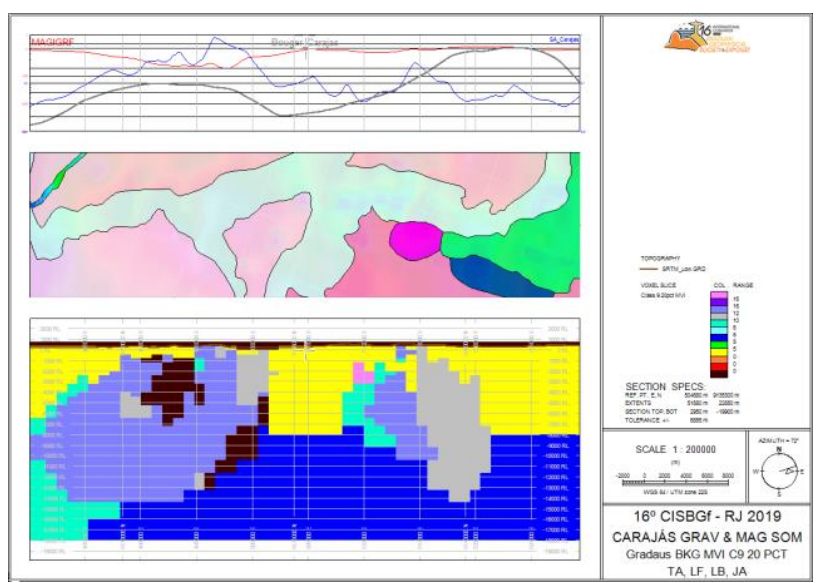

Figure 8: Gradaús MVI SOM classes, plan view with geological map and profiles from surface data.

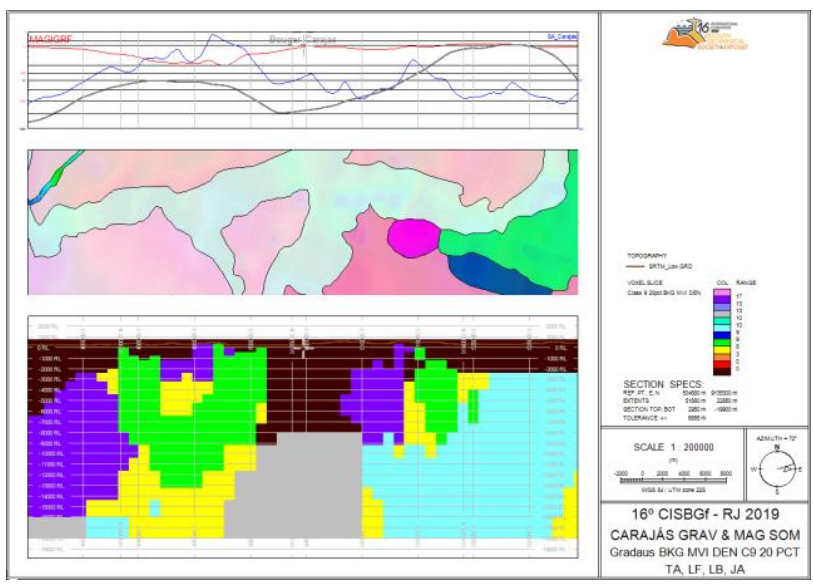

Figure 9: Gradaús MVI and Density SOM classes, plan view with geological map and profiles from surface data.

\section{Conclusions}

MVI applied to regional airborne magnetic data combined with SOM classification proved to be an efficient tool to automatically identify mineral exploration targets, allowing to confirm known deposits and suggest new targets for further investigation. When other geophysical data like gravity is available, the results are further enhanced.

In the case of the Sossego and Salobo copper mines, the addition of the density model provides a clear definition not only from the orebody but also from the host rocks.

The response of the Gradaús target to the applied methodology recommends further investigation of this target.

The models were created using unconstrained inversion as the authors didn't have access to other data, but it is always recommended to use constrained inversion when additional information is available.

\section{Acknowledgments}

We would like to thank CPRM for providing public access to the airborne geophysical survey and Geosoft Latinoamerica team for their support and stimulating discussions.

\section{References}

Aisengart, T., Ando, J. L., Batista, L., Ferreira, L.C., 2018. Técnica de self-organizing maps (SOM) aplicada aos modelos regionais de densidade e vetor de magnetização $(\mathrm{MVI})$ da provincia mineral de Carajás. $49^{\circ}$ Congresso Brasileiro de Geologia, Rio de Janeiro, Brasil.

Aisengart, T., Ando, J. L., Barbosa, R. D., Rech, M., Pereira, J.G., 2017. Caracterización de cuerpos intrusivos de la provincia alcalina de Goiás usando inversión geofísica y Self Organizing Maps. XVI Congreso Colombiano de Geologia, Santa Marta, Colombia.

Aisengart, T. 2015. Qualitative and Quantitative Magnetization Vector Inversion applied to the Pirapora Anomaly. 14th International Congress of The Brazilian Geophysical Society, Rio de Janeiro, Brazil.

CPRM, 2008. Geologia e Recursos Minerais do Estado do Pará Escala 1:1.000.000. Belem Programa Geologia do Brasil PGB.

CPRM, 2015. Mapa Geológico Simplificado do Brasil, escala: 1:6.000.000. Serviço Geológico do Brasil.

Ellis, R. G., de Wet, B., MacLeod, I. N., 2012. Inversion of magnetic data for remanent and induced sources. ASEG Extended Abstracts, 1-4.

Zhdanov, M. S., and Portniaguine, O., 2002. 3-D magnetic inversion with data compression and image focusing, Geophysics, 67, 1532-1541.

Zhdanov, M. S; 2002; Geophysical Inverse Theory and Regularization Problems, Methods in Geochemistry and Geophysics. Elsevier Science BV, Amsterdam, Netherlands, v. 36. 